\title{
Reconstructive management of degloving trauma of male external genitalia using dermal regeneration template: A case report
}

\author{
Luigi Valdatta ${ }^{\text {a }}$, Francesca Maggiulli ${ }^{\text {b,* }}$, Stefano Scamoni ${ }^{\text {b }}$, \\ Igor Pellegatta ${ }^{c}$, Mario Cherubino ${ }^{a}$
}

a University of Insubria, Ospedale di Circolo and Fondazione Macchi, Varese, Italy

${ }^{\mathrm{b}}$ Ospedale di Circolo and Fondazione Macchi, Varese, Italy

' University of Insubria, Varese, Italy

Received 6 December 2012; accepted 2 June 2013

\author{
KEYWORDS \\ Male external \\ genitalia; \\ Reconstructive \\ procedures; \\ Degloving trauma; \\ Integra ${ }^{\circledR}$; \\ Dermal regeneration \\ template
}

\begin{abstract}
Summary Traumatic injuries of male external genitalia are rare and not usually life threatening; however, they can have psychological repercussions. The reconstructive management of these lesions is challenging and articulated. We report the case of a 38-year-old farmer suffering from a degloving wound on the external genitalia. The first reconstructive step used to treat the wound was the incorporation of a dermal regeneration template (Integra $\left.{ }^{\circledR}\right)$ and accordingly partial-thickness skin grafts and local flaps. The follow-up 16 months after the first treatment was satisfying; sexual function had been restored.

(C) 2013 British Association of Plastic, Reconstructive and Aesthetic Surgeons. Published by Elsevier Ltd. All rights reserved.
\end{abstract}

Male external genitalia traumatic injuries are rarely a lifethreatening condition; nevertheless, adequate action must be taken in order to avoid sexual and psychological complications.

\footnotetext{
* Corresponding author. Division of Plastic and Reconstructive Surgery, University of Insubria, Ospedale di Circolo and Fondazione Macchi, Viale Borri 57, Varese 21100, VA, Italy. Tel.: +390332 278150; fax: +39 0332278474.

E-mail addresses: luigi.valdatta@uninsubria.it (L. Valdatta), francesca.maggiulli@live.it, chirplas@gmail.com (F. Maggiulli), stefano.scamoni@libero.it (S. Scamoni), igor.pellegatta@me.com (I. Pellegatta), mario.cherubino@gmail.com (M. Cherubino).
}

In this article we report the case of a male external genitalia degloving injury and its reconstruction with the Integra ${ }^{\circledR}$ dermal substitute. Use of Integra ${ }^{\circledR}$ in degloving male external genitalia is often the right common reconstructive alternative.

\section{Case report}

A 38-year-old man arrived in our department presenting a wide degloving wound on the external genitalia after an accident with a farm grinding wheel. The penis skin defect reached until the superficial dartos fascia and the degloving

1748-6815/\$ - see front matter @ 2013 British Association of Plastic, Reconstructive and Aesthetic Surgeons. Published by Elsevier Ltd. All rights reserved. http://dx.doi.org/10.1016/j.bjps.2013.06.003 
trauma was concentrated on the common tunica albuginea of the testis. The corpora cavernosa, testicular parenchyma and anal sphincter were spared (Figure 1). Trauma did not affect either the glans or the deep tactile sensitivity of the penis. The general condition was stable and blood loss was minimal. After an adequate sedation of the patient, catheterism, several washings and a non-viable tissue removal, we came to the understanding that a primary reconstruction with replant or fillet flap was not possible due to the massive impairment of the skin tissue integrity. A temporary invagination of both testes inside the perineal pouch was performed to allow an adequate protection (Figure 2). We decided to wait before applying the grafts as they can create scarring contracture when positioned directly over the dartos fascia; in that way we avoided penis incarceration when there is an erection.

Over the following days, antibiotic therapy was prescribed and advanced dressings were used. Nineteen days later, the penis skin was recreated with Integra ${ }^{\circledR}$ splitthickness skin grafts and a scrotal-like pouch were shaped using a circumferential local flap from the anterior abdominal region as support for the Integra ${ }^{\circledR}$ double invaginated sheet. We used a pedicled skin flap transposition, characterised by random vascularisation transferred from the groin to the groove penis - scrotum. This local flap allowed us to create a sort of skin anchor in order to sustain the newly created Integra ${ }^{\circledR}$ scrotal pouch. Despite the presence of fungal and bacterial infections, no complications in dermal matrix integration were observed.

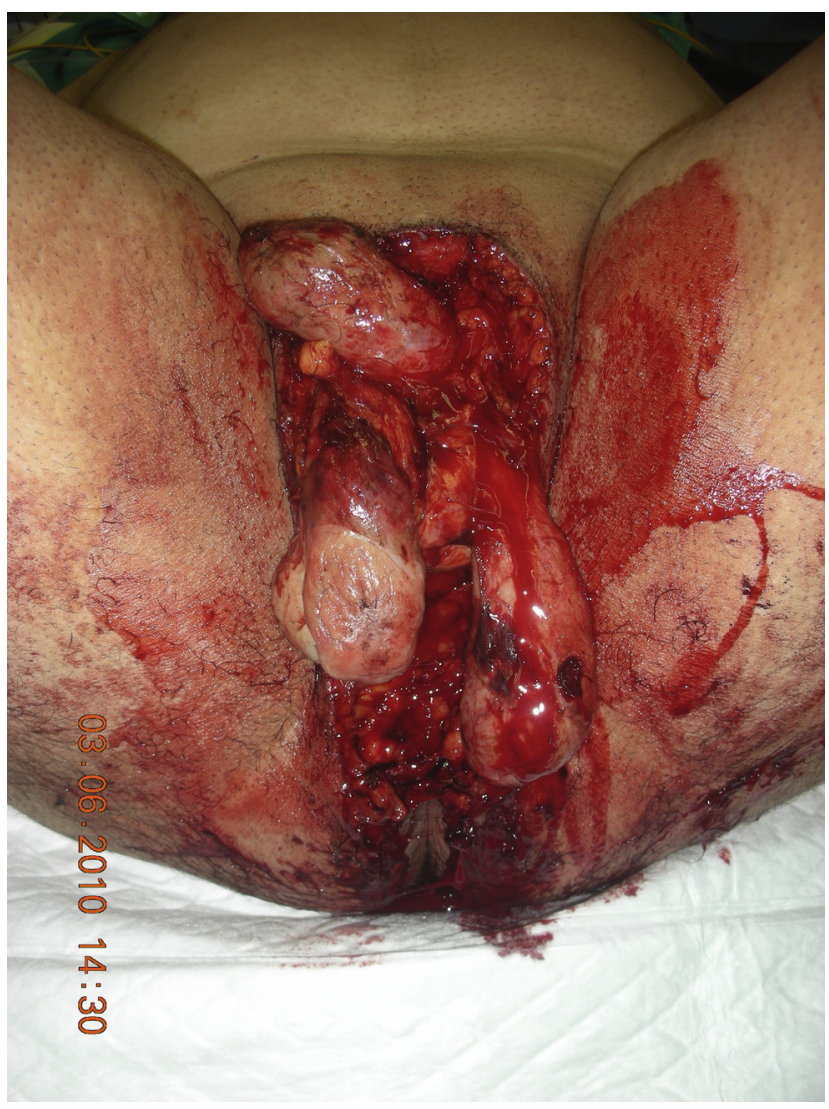

Figure 1 Traumatic degloving of external male genitalia.

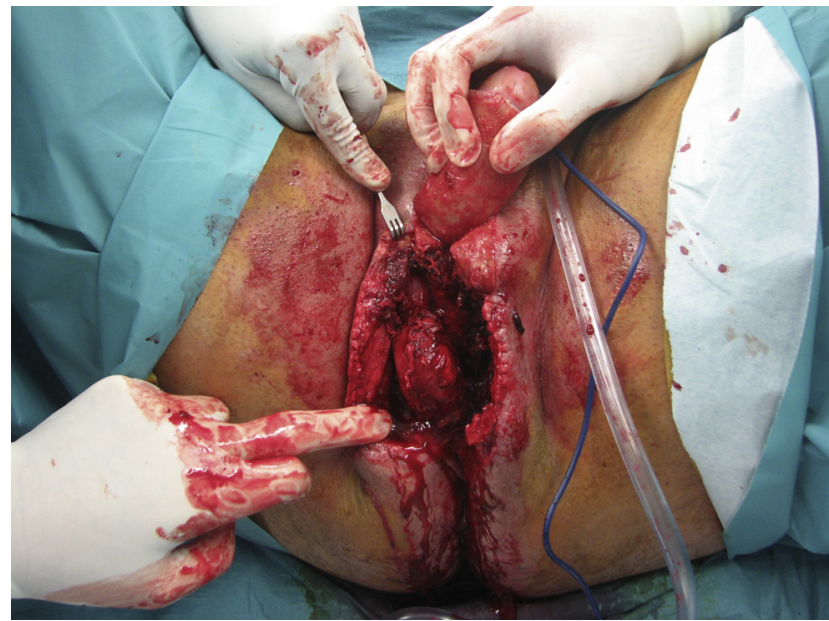

Figure 2 Results after invagination of testicles. Perineal region was spared, scrotal and penile skin was completely lost.

Antibiotic therapy and advanced medication were maintained until the coverage of the dermal regeneration template with split-thickness skin grafts, performed 22 days later (Figure 3).

\section{Results}

No complications related to Integra ${ }^{\circledR}$ incorporation were observed. Low colony forming unit (CFU) bacterial and fungal infections were found after wound swab execution and they were treated with specific antibiotic and antifungal therapy and frequent washings with antiseptic solutions. The patient reported that sexual pleasure with ejaculation but without erection was reached after only 2 months after the trauma, while an erection with ejaculation and sexual pleasure were achieved after 6 months,

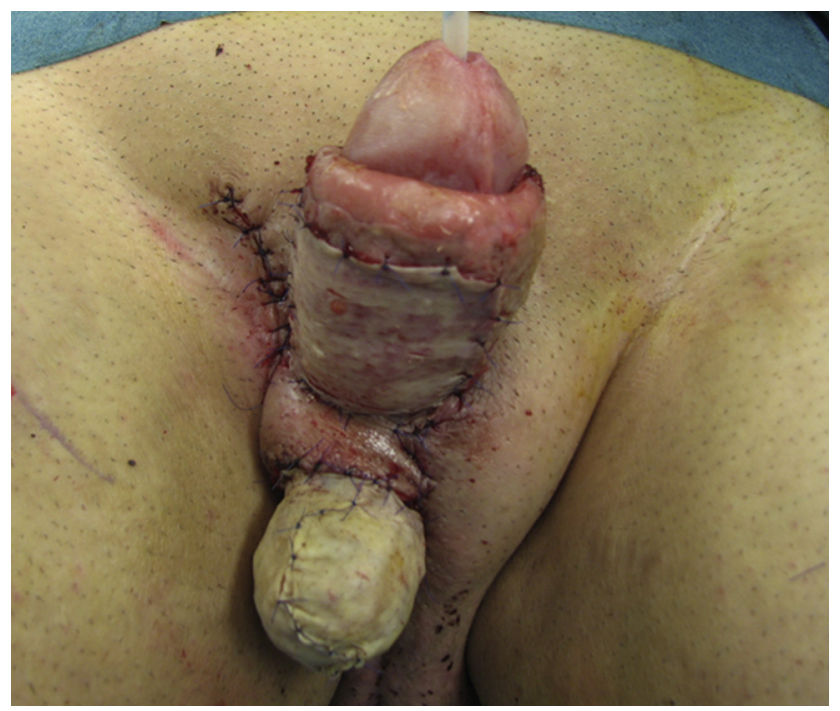

Figure 3 Result after final phase of reconstruction with splitthickness skin graft. Previously scrotal region was created with local flap from anterior abdominal region in support of Integra ${ }^{\circledR}$ double invaginated sheet. 


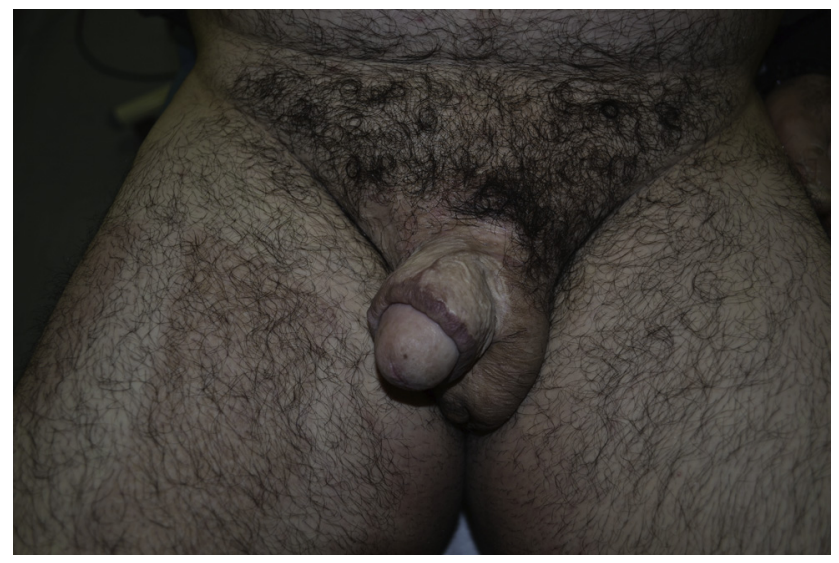

Figure 4 Follow-up after 16 months.

during a first sexual intercourse. Furthermore, the spermiogram revealed average concentration, motility and morphology of spermatozoa.

After a 16-month-follow-up, no urination disorders were noted; a minimal retraction when the penis is quiescent and modest, but without pain, when in erection was observed. The morphology of the penis appears acceptable (Figure 4).

\section{Discussion}

In scrotal reconstruction, manifold options are available. Direct reconstruction with grafts is the most commonly used technique ${ }^{1}$ : it is simple and in most cases successful but sometimes needs surgical revision due to the contraction and distortion of the scrotal skin, causing problems to the aesthetical result. Flaps built from the thigh, groin and perineum represent excellent bases for scrotal reconstruction but they have limits. First, the skin of the recently mentioned anatomic areas does not have the same elasticity and consistence as that of the scrotal skin. Moreover, in the case of necrotising fasciitis (Fournier gangrene) preparation of the flap could be difficult. ${ }^{2}$ In order to maximise the dimensions of the skin used for the flap design, tissue expanders have been used. This technique could be useful when the defect is vast but requires a twostep and not immediate surgical procedure and can be uncomfortable for the patient. Use of Integra ${ }^{\circledR}$ and skin grafting in scrotal reconstruction has not been previously reported in the literature. We believe that, although it is not an immediate procedure like the management of scrotal defects in reconstruction with grafts or flaps, the use of a dermal regeneration template gives the testicles proper protection and, once the skin graft is applied, allows us to obtain the natural elasticity of the skin. Furthermore, its use would be desirable in situations when the defect is wide and local flaps cannot be used (necrotising fasciitis).

In the literature ${ }^{3}$ the traditional treatment of complete avulsion trauma of male external genitalia, as reported above, consist of a first step of invagination of testis and debridement of non-viable tissue without using an avulsed skin flap for reconstruction and after a period of clinical observation, a coverage of the defect with split-thickness skin grafts. Moreover, local lotus petal flaps ${ }^{4}$ represent an interesting option to face the reconstruction of the scrotal region.

Manifold complications ${ }^{5}$ might appear in the postsurgery period, both immediate such as flap necrosis or infection and late such as scar retraction, urethral stenosis, erectile dysfunction and infertility.

Thanks to the dermal regeneration template, it is possible to face immediately traumas that cause a wide skin defect as in the example we have just examined. Immediate reconstruction with Integra ${ }^{\circledR}$ would allow us to reduce the infectious complication and prepare a florid wound bed for the following coverage with skin grafts.

\section{Conclusion}

Notwithstanding the rarity and the usually not lifethreatening nature of the degloving trauma of male external genitalia, they can provoke serious social and psychological problems for the patient, should the reconstructive procedure fail.

Hence, in the reconstructive management of this type of lesions every effort ought to be made to avoid scar retraction complications, quite likely in treatment based only on skin graft application.

This report demonstrates how a dermal regeneration template could represent a valid option in the treatment of male external genitalia degloving injuries.

\section{Acknowledgements}

The authors have no acknowledgements to make and no funding sources were used during the study.

\section{References}

1. Gencosmanoğlu R, Bilkay U, Alper M, Gürler T, Cağdaș A. Late results of split-grafted penoscrotal avulsion injuries. $J$ Trauma 1995;39(6):1201-3.

2. Ferreira PC, Reis JC, Amarante JM, et al. Fournier's gangrene: a review of 43 reconstructive cases. Plast Reconstr Surg 2007; $119(1): 175-84$

3. Morey AF, Metro MJ, Carney KJ, Miller KS, McAninch JW. Consensus on genitourinary trauma: external genitalia. BJU Int 2004;94(4):507-15.

4. Payne CE, Williams AM, Hart NB. Lotus petal flaps for scrotal reconstruction combined with Integra resurfacing of the penis and anterior abdominal wall following necrotising fasciitis. $J$ Plast Reconstr Aesthet Surg 2009;62(3):393-7.

5. Bartkiw TP, Goldfarb B, Trachtenberg J. Male genital trauma: diagnosis and management. Int J Trauma Nurs 1995;1(4): 99-107. 